\title{
Commission for the Geological Map of the World (CGMW)
}

\section{http://www.cgmw.org}

The Commission for the Geological Map of the World (CGMW), the oldest geoscience organization after the International Geological Congress (IGC), was created in 1881 during the 2nd IGC in Bologna.

The CGMW is in charge of the conception, promotion, coordination, preparation and the publication of maps at small scale of the continents and oceans, pertaining to all the fields of Earth sciences (geology, hydrogeology, tectonics, metallogeny, resources, natural hazards, climate, seafloor, etc.).

\section{Organization}

The CGMW is a non-profit scientific and educational body with headquarters in Paris. It is affiliated to the IUGS since the creation of the latter in 1961. It is recognized by UNESCO as a NGO of category A and is thus entitled receive funds from this organization, with which an important number of maps are actually co-published.

Geological surveys of all the countries of the World are statutory members of the CGMW. A bureau composed of a President, a Secretary General and leaders of the different Subcommissions, thematic (tectonic, metamorphic, metallogenic maps, etc.) or regional (Europe, Northern Eurasia, Africa, etc.) coming from all the continents, ensures the well running of the commission.

To produce its maps, the CGMW relies on the support provided by the international scientific community and the cooperation agreements it establishes with Geological surveys, laboratories of universities, oceanographic institutes and industrial firms, according to the requirements of each project.

\section{Achievements and production}

The different maps published directly by the CGMW or in conjunction with UNESCO (Geological Atlas of the World at 1:10 M, geological maps of various world areas, cf. South America, Middle East, etc.) are listed in the catalogue of the CGMW available on line at www.cgmw.org. Among the most recent realizations are:

- The Geological Map of the World, at the 1:25 M scale (3 sheets) and at a reduced format $(1: 50 \mathrm{M})$ on a single sheet, more fitted to teaching purposes. A digital interactive version of the map is also available on $\mathrm{CD}$.

- The Seismotectonic Map of the World at 1:25 M scale, which was presented in the former issue of Episodes (vol. 25, $\mathrm{N}^{\circ} 2$, 112-115).

- A set of two maps (total of 4 sheets) at the 1:25 M scale showing the distribution of climatic zones, ice caps, deserts, different types of vegetation, etc. during th e last two climatic extremes (18 000 and 8000 yrs B.P. respectively).

- The International Metallogenic Map of Africa at 1:5 M scale in four sheets.

\section{Projects}

18 mapping programmes are currently in progress or being launched. They include among others:

- 2 projects especially undertaken for the next IGC (Florence, 2004); one concerns the Geodynamic map of the Mediterranean and neighbouring regions with representation of the active faults, earthquakes, volcanism, etc., and the other is a devoted to a new Metamorphic and structural map of the Alps.

- The international tectonics maps at 1:5 M scale of Africa and Asia.

- $\quad$ The Geological map of Europe at 1:5 M scale (IGME 5000 project).

- A global hydrogeological map at 1:25 M scale, whose digital version will include a complete database of the water resources of each region of the World.

- A series of maps of the oceans at the scale of 1:10 M, that started with the structural map of the Indian Ocean, whose completion is expected for 2003 and includes, besides a detailed bathymetry, the age of the ocean floor, the transform faults, sediment thickness, etc. After this first realization, the next phases of the programme will be devoted to the Arctic, Northern Atlantic, the Caribbean and the SW Pacific.

A number of these mapping programmes will be presented, either in their final or draft form, at the IGC in Florence.

\section{Perspectives}

The realization of the maps has followed the evolution of digital cartography. Our publication policy has been adapting progressively to the user's demands at the same time that it has maintained the traditional printed maps. On this respect, a global consideration on the mapping techniques of the 21 st century has been initiated by the CGMW with the view of promoting the use and diffusion of digital cartography and opening new paths for the search and establishment of international standards.

\section{Contacts}

For more information on CGMW activities or receive a catalogue of CGMW maps, contact the business office or the General Secretary:

Dr. Philippe Rossi

CGMW

77, rue Claude-Bernard 75015 Paris, France

Phone: +33147072284

Fax : +33143369518

E-mail: ccgm@club-internet.fr

www.cgmw.org

Prof. Jean-Paul Cadet

President of CGMW

University $P \& M$ Curie

Paris, France 